\title{
A Study on Cases of Fatal Burns and Their Preventability
}

\author{
Ariyarathna HTDW* \\ Department of Forensic Medicine, Faculty of Medical Sciences, University of Sri Jayewardenepura, Gangodawila, \\ Nugegoda, Sri Lanka.
}

\begin{abstract}
Introduction: Although the demography of burns is frequently studied a number of preventable deaths have been reported warranting a justification. Prevention is primarily associated with the addressing of root causes/underlying causes. Mere statistics related to fatalities of burns without identification of the underlying causes do not serve the purpose of prevention. Demography of burn mortalities, strengths and weaknesses of the current practices are addressed to achieve primary prevention.
\end{abstract}

Method: The postmortem reports of fatal burn (dry burns) cases were collected from the respective forensic pathologists of the Office of the JMO at Colombo South Teaching Hospital from August 2015 to August 2020. All the postmortem reports were retrospectively studied in order to collect data. The data was analyzed with the SPSS software to study the demography of the burn fatalities.

Results: There were 54 deaths due to burns with male to female ratio being 1:3 (13:41) and the mean age was 51 years (SD of \pm 23.8 ). Accidental burns were the commonest followed by suicides. Kerosene and related apparatus were the main culprit followed by flames (caused by diesel/ petrol) and burns due to Liquefied Petroleum Gas (LPG). With the study findings one of the stipulations was that a number of deaths could have been prevented with simple, yet effective interventions.

Conclusion: It is futile to accumulate mortality statistics related to dry burns, unless they are used for preventive purposes. In this regard, a Forensic Pathologist (FP) can play an important and a substantive role in the prevention of such injuries. There is no provision to obtain a detailed history from ward patients by clinicians as the number of patients are more. Whereas a FP encounters only a few deaths a year enabling him to study the incidents in detail to identify the circumstances or underlying causes, in order to help in the prevention of unwanted deaths due to dry burns.

Keywords: Mortality due to burns, cause for the burn, role of the Forensic Pathologist, ICD 10

Received: 28 Nov 2020, Revised version accepted: 19 Dec 2020, Published: 31 Dec 2020. *Corresponding author: Ariyarathna HTDW, $\triangle$ email: ariyaratna@ @sp.ac.lk (D) ORCID: https://orcid.org/0000-0002-4266-5508

Cite this article as: Ariyarathna HTDW. A Study on Cases of Fatal Burns and Their Preventability. Medico-Legal Journal of Sri Lanka. 2020;8(2):1-6. DOI: http://dx.doi.org/10.4038/mljsl.v8i2.7418

Copyright: @ 2019 with the Medico-legal Journal of Sri Lanka.

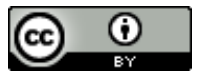

This is an open-access article distributed under the terms of the Creative Commons Attribution 4.0 International License, which permits unrestricted use, distribution, and reproduction in any medium provided the original author and source are credited.

\section{Introduction}

Forensic Pathologists/Judicial Medical Officers (FPs/JMOs) often are tasked with the investigation of cases of unnatural deaths, as a general process of the overall criminal investigation system. However, although crime prevention and investigations of crime is the primary purpose, of such tasks, their secondary purposes are of immense value, because all such details gathered in the primary investigations, can be in turn used for the prevention of such unnatural deaths including burns, which is for the greater good. Mortality and morbidity due to burns are studied under the category of "injury surveillance "in Sri Lanka. The definition of surveillance is "the systematic collection, analysis, interpretation, and dissemination of data, for the purpose of taking appropriate action". ${ }^{[1]}$ One of the most important end-point, quality control parameters is the mortality statistics of a given country. The nine different provinces in Sri Lanka have their own 
different epidemiological, geographical, occupational and economic factors. So each hospital is responsible to provide the exact details to the central Epidemiology Unit in order to formulate accurate statistics. This retrospective data analysis was performed at the Colombo South Teaching Hospital, to obtain an in-depth understanding of these different factors, circumstances and also more importantly to better understand the strengths and weaknesses of the current statistics.

\section{Methodology}

A retrospective data analysis was performed, on five years of data regarding deaths due to burns, spanning the period from August 2015 to August 2020 of the cases recorded at the Colombo South Teaching Hospital. This study was a collection and analysis of secondary data and analyzed with the SPSS software 21. All the postmortem reports obtained upon request from the respective FPs (deaths due to burns) were perused for the required data. The ethical clearance was granted from the Ethical Review Committee of the hospital. Deaths due to electrocution and lightening have been excluded.

\section{Results}

The total number of postmortems done during the period of 5 years was 4804 and the number of deaths due to burns was 54 resulting in a $1 \%$ of deaths were due to burns.

\section{Sex/ gender of the sample}

The sample size was $54(\mathrm{~N}=54)$ and of them 41 (76\%) were females. There were 13 males $(24 \%)$.

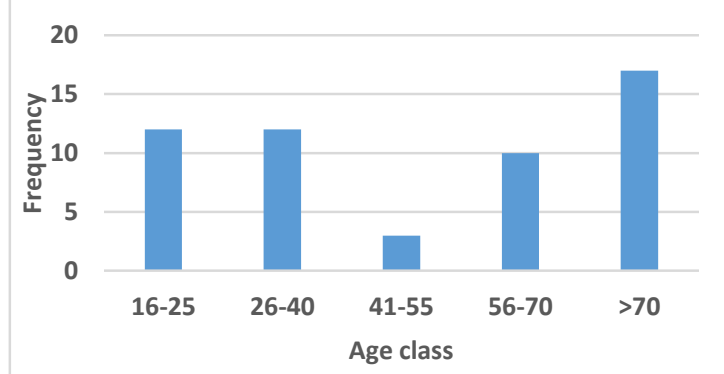

Figure 01. The distribution of age in each class of age

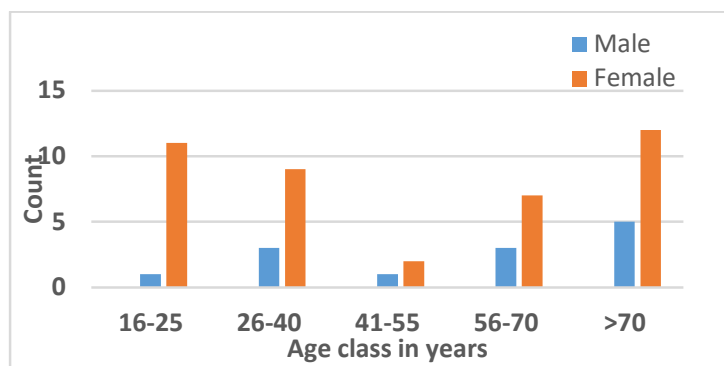

Figure 2: Distribution of burns by age group/classes (years) and sex.

The age class of 41-55 did not show much of a difference among both sexes. Females were always the most affected while the difference is much more towards the young.

\section{Circumstances of death of the deceased}

It had been identified 30 deaths $(56 \%)$ as accidental and 21 suicides $(39 \%)$ while the circumstance of death was unable to be identified in three incidents $(6 \%)$.

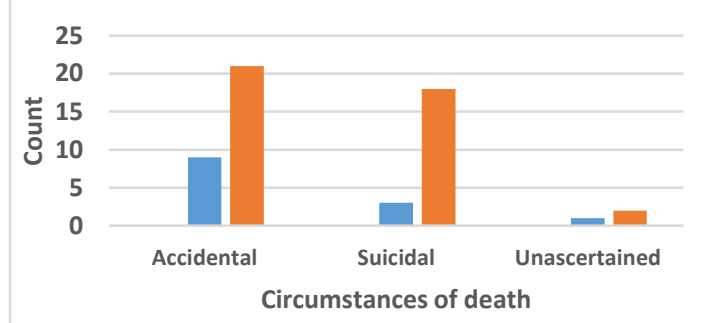

Figure 3: Association of the sex/gender with the circumstances of death.

There is a much difference among the both sexes in suicides when compare to the other circumstances of accidental and unascertained.

Status of alcohol at the time of the incident $47(87 \%)$ individuals were indicated to not have consumed alcohol at the time of death and the status of alcohol was inconclusive in 7 (13\%) individuals.

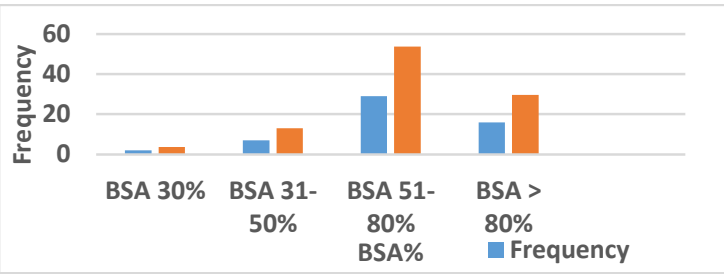

Figure 04: The affected Burn Surface Area (BSA) of the deceased 
The BSA $51-80 \%$, included most of the victims and followed by the $81-100 \%, 31-50 \%$ and $0-30 \%$. The mean BSA was $72 \%$.

Table 01: Source of burn

\begin{tabular}{lr}
\hline Source of burn & $\begin{array}{r}\mathbf{N = 5 4} \\
\text { \% (n) }\end{array}$ \\
\hline Kerosene & $46(25)$ \\
Petrol/Diesel & $4(02)$ \\
LPG & $9(05)$ \\
Other & $33(18)$ \\
Not ascertained & $7(04)$ \\
\hline
\end{tabular}

The majority had died due to the connectedness with kerosene $(\mathrm{n}=25,46 \%)$. It was mostly by accidental burns due to the ill effects of kerosene stoves. The category "other" includes house fires etc.

Table 02: Preventability of the incident

\begin{tabular}{lr}
\hline Preventability of the incident & $\begin{array}{l}\text { N=54 } \\
\text { \% (n) }\end{array}$ \\
\hline Negligence of the victim & $50(27)$ \\
Negligence of the employee & $02(01)$ \\
Merely an accident & $13(07)$ \\
Not ascertained & $35(19)$ \\
\hline
\end{tabular}

The preventability of the incidents was assessed according to the opinion of the FP. There had been occasions where it was difficult to make an assumption about the preventability $(\mathrm{n}=19,35 \%)$. Negligence of the victim was the commonest response $(\mathrm{n}=27,50 \%)$ followed by accidents $(\mathrm{n}=7,13 \%)$. One death $(1.9 \%)$ was due to the negligence of the employee.

Table 03: The period of hospitalization

\begin{tabular}{lr}
\hline $\begin{array}{l}\text { Time since the incident and } \\
\text { death }\end{array}$ & $\begin{array}{l}\mathbf{N = 5 4} \\
\mathbf{\%}(\mathbf{n})\end{array}$ \\
\hline within 6 hours & $02(01)$ \\
within 12 hours & $06(03)$ \\
within 24 hours & $20(11)$ \\
within 2-5 days & $17(09)$ \\
within 5-10 days & $17(09)$ \\
$>$ 10 days & $20(11)$ \\
Dead on admission & $18(10)$ \\
\hline
\end{tabular}

Most of the victims; that is $44(81 \%)$ were admitted alive subsequent to their burn injuries. Ten individuals $(18 \%)$ were dead by the time of admission. One deceased had survived less than 6 hours and the rest of the patients had survived for 3 11 days.

\section{Discussion}

The discussion is based on three main aspects: the results of the present study, the prevailing data collection related to injury prevention in Sri Lanka, and ways in which forensic pathologists and the epidemiological unit can further improve the usefulness of the statistics.

Injuries are a major global health problem and accounted for $9 \%$ of all deaths, annually. ${ }^{[2]}$ According to the WHO, injuries are defined as a bodily lesion resulted from exposing to physical agents such as mechanical energy, heat, electricity, chemicals, ionizing radiation or from the impairment of the essential functions by sudden lack of essential agents such as air, water and warmth as in drowning, strangulation or freezing. ${ }^{[2]}$ Injuries could be from the subcategories of intentional injuries ('selfinflicted injuries, interpersonal violence and collective violence') and unintentional violence (road traffic injuries, drowning, burns/fires, falls and poisoning etc). ${ }^{[2]}$ According to epidemiological model of prevention of injuries, which comprises three stages, namely, primary prevention: by reducing the risk or the exposure of occurring injuries, secondary prevention: by preventing more serious consequences once sustained injuries, tertiary prevention: by rehabilitating physically and psychologically. The primary prevention is to be achieved by addressing the underlying causes and risk factors. ${ }^{[2]}$ Therefore, the identification of the underlying cause/s is key in primary prevention. The age group that contributes most for the economy and the education of a country, is 15 to 44 years according to literature and the same age group is affected by injuries the most. ${ }^{[3]}$ Most injuries are predictable and so the best solution is, prevention. ${ }^{[3]}$

The number of fatalities during the five-year period was $54(\mathrm{~N}=54)$. Male to female ratio was $1: 3$ and the mean age was 51 in years and SD was \pm 23.8 and the age was ranging from 18 years to 90 years. The reason for not having very young children may be the practice of transfer of minors to the children's hospital for specialized management. The majority of the victims were seen in more than 70 year old age group (31\%) and the least from the age group of 41 -55 years, showing biphasic model (Fig:1). In each age category, females were mostly affected (Fig:2). But in many studies the mostly affected age group had been identified as young individuals..$^{[4,5,6]}$ The same male to female ratio was found in a study done in India. ${ }^{[7]}$ In the present study, the majority had died due to accidental causes, $\mathrm{n}=30(56 \%)$ followed by suicidal circumstances, $n=16(39 \%)$ In all three types of accidents, suicides and in unascertained group females are higher in number. The difference or the gap of the number of males and females that were affected in the accidental group and the suicidal group is marked and striking in the category of 
suicides (Fig:3). In a study done in Egypt, it had been reported that accidental burns were $55.7 \%$ and suicidal burns were $22.6 \%$. The number of accidental deaths was nearly similar to this study with the above figure though the number of suicides with immolation was more in Egypt. In the same study a male preponderance of burn mortalities has been noted. ${ }^{[8]}$

Thirty seven $(87 \%)$ individuals had not consumed alcohol at the time of the incident. In seven cases the alcohol status was not known. The burn surface area ranged from $25 \%-100 \%$. The mean Burn Surface Area (BSA) in this study was $72 \%$. (Fig:4) Studies done in Angola and Jaipur had indicated that when the BSA was more than $40 \%$ a $100 \%$ mortality and when the BSA was in $40 \%-50 \%$, it had been $80 \%$ mortality rates had been recorded respectively. ${ }^{[9]} \mathrm{In}$ a study done in India the BSA above $40 \%$ was fatal ${ }^{[10]}$ and in this study four individuals even with $25-35 \%$ had died out of which some were quite young even without co-morbidities. Kerosene was the major culprit, $\mathrm{n}=25$ (46\%), LPG involvement was seen in 5 individuals (9\%), and flame from other sources such as house fires and other sources of fires had been responsible in $\mathrm{n}=18$ individuals (33\%) (Table:1). In twenty seven occasions (50\%) it had been identified as due to the negligence of the victim. In seven occasions (13\%), it had been identified as unpreventable by the respective forensic pathologists (Table:2). 20\% ( $\mathrm{n}=11)$ of those who have been admitted to a hospital ward had been treated for more than 10 days before their demise. (Table:3) The suffering, cost and the man power utilized for burn management is considerable. An in depth study of the individual cases would definitely, identify the flaws and weaknesses or negligence of the respective causes when deaths are unwarranted. An adequate emphasis and the thoughtful intervention will definitely help to minimize the mortality rates. The author's main concern is that the preventability of such deaths through in-depth studies. It can easily be achieved through the work of forensic pathologists as they investigate all unnatural deaths in-depth, as to how it occurred etc. The knowledge about International Classification of Diseases (ICD) and documentation of the findings are also an important source that needs further emphasis as these type of entries can also be utilized for prevention purposes.

Indoor mortality and morbidity registers (IMMR), injury surveillance and Annual Health Bulletins are comprised of data compiled in order to understand the health issues in Sri Lanka. IMMR only records the data pertaining to admitted patients. Annual Health Bulletin is also somewhat based on IMMR.
Out of these two, injury surveillance is the best available data for the mortality of burns at the moment in Sri Lanka, as it concentrates on injuries.

The most important fact that was able to be highlighted through this research is the deficiencies in the identification of underlying causes/risk factors or circumstances for the burns. Statistics may provide the number of suicides, accidents or homicides in figures. The benefit from such details are less unless the underlying causes are identified. The cause of the primary injury and its prevention is one of the most important aspects even though secondary and tertiary aspects are also highly important. The primary prevention is not perfect, until due concentration is paid on documenting and studying the risk factors/circumstances or underlying cause. The number of patients that are managed by a hospital due to burn injuries is far greater than the number of deaths and therefore it is not practical to scrutinize such incidents. But scrutiny of mortalities is an achievable target. For an example why females are being more prone to die due to gas related issues? Whether it is due to poor maintenance of gas cookers and regulators, or whether the kerosene cookers/stoves are of poor quality? There is no benefit, in simply providing only numbers of these accidents, suicides, etc unless there is a mechanism to scrutinize the risk factors or circumstances and then to come up with remedial actions. Therefore, the responsibility of a forensic pathologist is all the greater, to provide the underlying causes/root causes in their postmortem examination reports. Moreover, it is also of no use for forensic pathologists to identify the underlying causes or risk factors and to have them recorded and kept on paper. There should be a mechanism of conveying the underlying causes to the authorities, as data to be addressed both in preventive and curative levels. So the author highlights through this research, the fact that mere data collection serves no purpose unless and until they are addressed through preventive and curative mechanisms. Prevention of at least a single death in the future means a great deal to the respective family, society and to the economy of a country as explained by "Accident Pyramid". [11] As doctors, our responsibility is to enter the records on the bed head tickets and postmortem reports as if the information is to be utilized by the data collectors based on ICD as the first step and then to implement a method to investigate cases in detail. Unless a doctor mentions a cause of death or the diagnosis of an injury in detail, in the designated place the medical statisticians tend to classify them under T30 as "unspecified burn injuries" from which no one will be benefited as expected. 
Chapter XIX of the International Statistical Classification of Diseases and Related Health Problems 10th Revision (ICD-10) Version for 2008 deals with Injury, poisoning and certain other consequences of external causes (S00-T98). T20T32 are for burns and corrosions. Although seemingly the classifications will seem somewhat complicated, once they are carefully studied they are very straightforward. If doctors code the incidents accurately, the correct data will be included in the current statistics formulated by the Ministry of Health, rather than categorizing all the incidents as burns and corrosions under T30 without a meaningful specification for the bodily region and the percentage. Instead there should be a practice of entering the underlying cause/risk factors or how the burn was caused within the limits of FPs thus enabling the analysis of the causes or risk factors further by a responsible authority in order to make interventions to prevent unwanted deaths.

According to the Indoor Morbidity and Mortality Register 2018, there had been 194 deaths islandwide with a ratio of male: female nearly 1:4 (all other burns and corrosions except eye and adnexa, $\mathrm{T}$ 30). ${ }^{[12]}$ Such data signifies only figures and not the underlying causes and the manner of death. So whichever, the data collected, in order for the data to have more meaningful use, in order to properly address these health issues, the adequate identification and classification of the causes, must be made a non-dispensable condition.

\section{Conclusion}

Mortality due to burns may be intentional and unintentional. Injury prevention surveillance, IMMR and Annual Health Bulletin assess the extent of the problem in Sri Lanka. Primary prevention is acquired through identification of the risk factors or root causes. Rather than having figures to represent the existing problem in the country, it is greatly beneficial to address the problem through identification of root causes and contributory factors. In this endevaour all the doctors in Sri Lanka including forensic pathologists should enter adequate details according to ICD in the Bed Head Ticket and in postmortem examination reports as if it is possible to group such conditions according to ICD. An in depth study of the root causes/underlying causes at least in unintentional fatal burn cases is strongly recommended in order to minimize such unwarranted deaths in Sri Lanka as such injuries are easily predictable and hence more easily preventable.

\section{Acknowledgments}

Dr. Samitha Sirithunga, (Consultant Community Physician, National Programme Manager (Injury Prevention), Ministry of Health, Mr. Sithum Manjika (Statistical Officer, Department of Community Medicine, University of Sri Jayewardenepura), Dr. P. Dasanayaka and Dr. SR Hulathduwa (Consultant Forensic Pathologists), Dr. ELPA Jayathilaka, Dr. PH Jayawardana, Dr. RMTS Weerasingha, Dr. PACT Kumarasiri, Dr. TNRD Mal, Dr. SPR Siriwardene, Dr. KLSV Karandana former demonstrators attached to the Department of Forensic Medicine, University of Sri Jayewardenepura, Sri Lanka are gratefully acknowledged for the guidance, statistical analysis and data collection.

\section{Disclosure statement}

Conflicts of interests: The authors declare that they have no conflicts of interest.

Funding: None

\section{References}

1. Liyanage T. Manual for the Sri Lanka Public Health Inspector: Epedemiology .Padukka: State Printing Corporation;2010. p. 229-73.

2. Ministry of Healthcare and Nutrition. Weekly Epidemiological report: Injuries - a Significant Public Health Problem in Sri Lanka .Vol. 37 No.40. [Cited 2020 Sep 24]. Available from: http://www.epid.gov.lk/web/images/pdf/wer/201 0/vol_37_no_40_english.pdf

3. Javatilleke A. Development and Piloting of National Injury Surveillance System of Sri Lanka. [Internet]. Tephinet.org. 2013; [cited 20 December 2020]. Available from: https://www.tephinet.org/tephinet-learningcenter/ tephinet-library/development-andpiloting-of-national-injury-surveillance

4. Kumar P, Wdhesh K, Mayank G. An Epidemiological Retrospective Study of Autopsied Dry Thermal Burn. Journal of Indian Academy of Forensic Medicine 2014;36(4):3636.

5. Aksoy N, Arli S, Yigit O. A Retrospective Analysis of the Burn Injury Patients Records in the Emergency Department, an Epidemiologic Study. Emergency 2014;2(3):115-20. PMID: 26495361

6. Kumara S, Ali W, Verma A, Pandey A, Rathore S. Epidemiology and mortality of burns in the Lucknow Region, India-A 5 year study. Burns 2013;39(8):1599-605. DOI: https://doi.org/10. 1016/j .burns.2013.04.008

7. Choudhary V, Kumar P, Kumar P, Kumar P, Kumar S. Epidemiological study of burn admissions in a tertiary burn care center of Bihar, 
India. Indian J Burns 2019;27(1):63-7.DOI: 10.4103/ijb.ijb_21_19

8. Afify M, Mahmoud N, Abd El Azzim G, El Desouky N. Fatal burn injuries: A five year retrospective autopsy study in Cairo city, Egypt. Egyptian Journal of Forensic Sciences 2012;2(4):117-22. DOI: https://doi.org/10.1016 /j.ejfs .2012.08.002

9. Pateria D, Thakur PS, Agrawal R, Singh BK, Tomar J. Autopsy based profile of death in burn cases- One year prospective study. Indian J Forensic Community Med 2018;5(4):236-9. DOI: https://doi.org /10.18231/2394-6776. 2018.0054

10. Mishra PK, Tomar J, Sane MR, Saxena D, Yadav A. Profile of Death in Burn Cases: A Post- mortem Study. J Indian Acad Forensic Med 2016;38(1):8-10. DOI: https://doi.org/ 10.5958/ 0974-0848.2016.00001.4.

11.Penkey S, Siddiqui N. A Review on Accident Pyramid and its Empirical Interpretation in Oil \& Gas Industry (Upstream). International Journal of Scientific and Research Publications 2015;5(1):1-3.

12. Ministry Of Health. Annual Health Statistics 2018, Sri Lanka. [Internet]. [cited 2020 Dec 19] Available from: http://www.health.gov.lk/moh_ final/english/others.php?pid=110. 